\title{
Exploring the Influence of Attitudes to Walking and Cycling on Commute Mode Choice Using a Hybrid Choice Model
}

\author{
Chuan Ding, ${ }^{1,2}$ Yu Chen, ${ }^{1,2}$ Jinxiao Duan, ${ }^{1,2}$ Yingrong Lu, ${ }^{1,2}$ and Jianxun Cui ${ }^{3}$ \\ ${ }^{1}$ School of Transportation Science and Engineering, Beijing Key Laboratory for Cooperative Vehicle Infrastructure System and \\ Safety Control, Beihang University, Beijing 100191, China \\ ${ }^{2}$ Jiangsu Province Collaborative Innovation Center of Modern Urban Traffic Technologies, Si Pai Lou No. 2, Nanjing 210096, China \\ ${ }^{3}$ School of Transportation Science and Engineering, Harbin Institute of Technology, Harbin 150090, China
}

Correspondence should be addressed to Jianxun Cui; cuijianxun@hit.edu.cn

Received 2 February 2017; Accepted 19 April 2017; Published 21 May 2017

Academic Editor: Guohui Zhang

Copyright (C) 2017 Chuan Ding et al. This is an open access article distributed under the Creative Commons Attribution License, which permits unrestricted use, distribution, and reproduction in any medium, provided the original work is properly cited.

\begin{abstract}
Transport-related problems, such as automobile dependence, traffic congestion, and greenhouse emissions, lead to a great burden on the environment. In developing countries like China, in order to improve the air quality, promoting sustainable travel modes to reduce the automobile usage is gradually recognized as an emerging national concern. Though there are many studies related to the physically active modes (e.g., walking and cycling), the research on the influence of attitudes to active modes on travel behavior is limited, especially in China. To fill up this gap, this paper focuses on examining the impact of attitudes to walking and cycling on commute mode choice. Using the survey data collected in China cities, an integrated discrete choice model and the structural equation model are proposed. By applying the hybrid choice model, not only the role of the latent attitude played in travel mode choice, but also the indirect effects of social factors on travel mode choice are obtained. The comparison indicates that the hybrid choice model outperforms the traditional model. This study is expected to provide a better understanding for urban planners on the influential factors of green travel modes.
\end{abstract}

\section{Introduction}

In recent years, the increasing automobile ownership and usage cause serious traffic problems and lead to a large amount of greenhouse gas emissions. The commuting trip, as one of the most important travel demands, often occurs at fixed times and contributes regular pressures to the traffic system. Unlike automobile modes, the nonmotorized travel modes (e.g., walking and cycling) are widely considered as sustainable patterns with low emissions [1]. Besides, using the travel modes of walking and cycling to work provides opportunities for people to get physical exercise. A reasonable amount of physical activities related to travel can help people keep healthy, which appears to be important for people in modern society. Bassett et al. [2] found that higher levels of active travel are usually correlated with a lower obesity rate. Briefly, the modes of walking and cycling may be the attractive alternatives for the short-distance commuting travels, especially in the compact China cities.

A literature review has identified a wide range of factors influencing an individual walking and cycling mode choice, such as sociodemographic factors, road infrastructure features, and environmental variables [3-10]. There is a growing body of research that focuses on the influence of psychological factors on the individual travel mode choice decision [11]. For example, the attitudes to the nonmotorized travel mode are perhaps one of the most important factors influencing the decision to walk or cycle. In developing countries like China, in order to improve the air quality, promoting sustainable travel modes to reduce the automobile usage is gradually recognized as an emerging national concern. Though there are many studies related to the physically active modes (e.g., walking and cycling), the research on the influence of attitudes to active modes on travel behavior is limited, 
especially in China. To fill up this gap, this paper focuses on examining the impact of attitudes to walking and cycling on commute mode choice and capturing the mediating role of attitudes played in travel mode choice decision.

The remainder of this paper is organized as follows. The following section presents a literature review related to our study. The third section describes the modeling approach used in this study. Data sources and description are provided in the fourth section. In the following section, empirical model results are analyzed. In the end, the conclusions and limitations of this study are provided.

\section{Literature Review}

With the environmental and healthy advantages in mind, the nonmotorized travel modes gain a growing attention. The influences of sociodemographic factors and built environment on the modes of walking and cycling have been widely investigated. An and Chen [8] found that the nonmotorized mode choice was strongly influenced by the factors of employment density, household income, and average sidewalk length. Using the logit model, Plaut [12] found that higher household income and housing price were correlated with lower propensity to walk or bicycle. As to the other sociodemographic factors (e.g., gender, age, and car ownership), similar empirical studies were conducted $[6,8,12-$ 15]. With regard to the influence from built environment, it is widely confirmed that the factors of density, diversity, and mixed land use have significant influences on the travel modes of walking and cycling $[8,9,16,17]$. Furthermore, there is an undeniable fact that travel mode choice behavior is affected, not only by the attributes of the modes themselves, but also by the unobserved factors. The cognitive psychology theory claims that preferences and behavior are correlated with perceptions and attitudes [18]. Generally, the attitudes determine the behavioral intentions, which are associated with the individual heterogeneity. The individual heterogeneity is a reflection of individual tastes, needs, values and goals, which is affected by experience, education, and so forth [1922].

In recent years, many exiting studies have adopted travel choice model by involving psychological variables (e.g., attitude and perception). Using a discrete choice model with latent variables, Johansson et al. [21] examined the commuter travel mode choice behavior. It is found that the environmental preferences increase the possibility of selecting a train mode. Using the data collected from a stated preference survey, Maldonado-Hinarejos et al. [23] incorporated the latent variables of attitudes, perceptions, and security concerns on bicycle use into the travel choice model. These study results indicate the necessary role of latent variables played in the multinomial logit choice model, and probike attitudes have positively significant effect on the cycling mode choice. Similar findings relate to the study conducted by Dill and Voros [24]. Moreover, cyclists usually take cycling as a healthy and environmental travel mode [25]. Using the survey data collected in the San Francisco Bay Area, Choo and Mokhtarian [26] found that travel attitudinal factors and personality characteristics significantly influenced individual vehicle type selections. Nurul Habib [14] examined the effects of willingness to walk, walking trip propensity, and walking distance on walking trip and indicated that young people are less possible to walk and females are more possible to walk. In particular, using advanced stated preferences survey data, Kamargianni and Polydoropoulou [27] examined the influence of teenagers' attitudes towards walking and cycling on mode choice behavior. It is found that willingness to walk and to cycle has a positive effect on the choice of those alternatives and a negative effect on the choice of a car.

With respect to the modeling methods, incorporating the latent variable into the discrete choice model is widely used. Though there is a growing literature on the influence of latent variable on travel mode choice, limited efforts have been made to capture the mediating role of the attitudes to travel mode. Different to the traditional discrete choice modeling approach, structural equation model (SEM) can not only obtain the direct effect, but also gain the indirect effect and total effect $[28,29]$. As shown in Figure 1, $X$, $Y$, and $M$ are exogenous variable, endogenous variable, and mediating variable, respectively. Assume that the direct effect of exogenous variable $X$ on the endogenous variable $Y$ is $\gamma$, and the indirect effect of exogenous variable $X$ on the endogenous variable $Y$ is $\alpha \times \beta$. Hence, the total effect of exogenous variable $X$ on the endogenous variable $Y$ is the sum of direct effect and indirect effect (i.e., $\gamma+\alpha \times \beta$ ). In the previous studies, though the latent factors are considered in the travel choice model, only the direct effects are taken into account without the indirect effect path. In this context, it would lead to inaccurate results, especially when the signs of the direct effect and indirect effect of the factor are opposite.

According to the literature, it is found that most existing studies only used the objective variables to investigate travel mode choice. A growing body of research is conducted to account for the objective variables (e.g., sociodemographic, modal attributes) and subjective variables (e.g., attitudes, perceptions) simultaneously. However, limited studies have been made on the influences of attitudes to walking and cycling on commute mode choice. Moreover, most studies are empirically examined in the western countries, while for the eastern countries like China, where the urban development level, traffic conditions, and living habits are quite different from western countries, more attention should be obtained. To fill up this gap, this paper focuses on examining the impact of attitudes to walking and cycling on commute mode choice. Using the survey data collected in China cities, an integrated discrete choice model and the structural equation model are proposed. By applying the hybrid choice model, not only the role of the latent attitude played in travel mode choice, but also the indirect effects of social factors on travel mode choice are obtained. The comparison indicates that the hybrid choice model outperforms the traditional model.

\section{Modeling Approach}

As a new kind of discrete choice models, hybrid choice model (HCM) combines the discrete choice model and the 


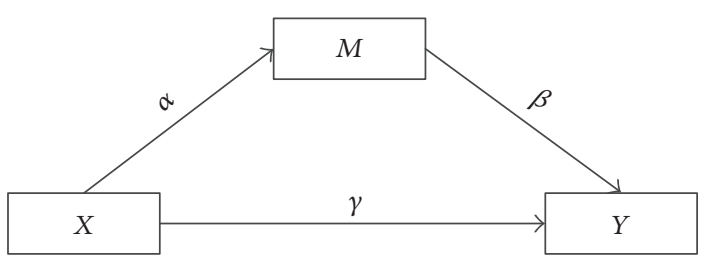

FIGURE 1: Modeling indirect effect diagram.

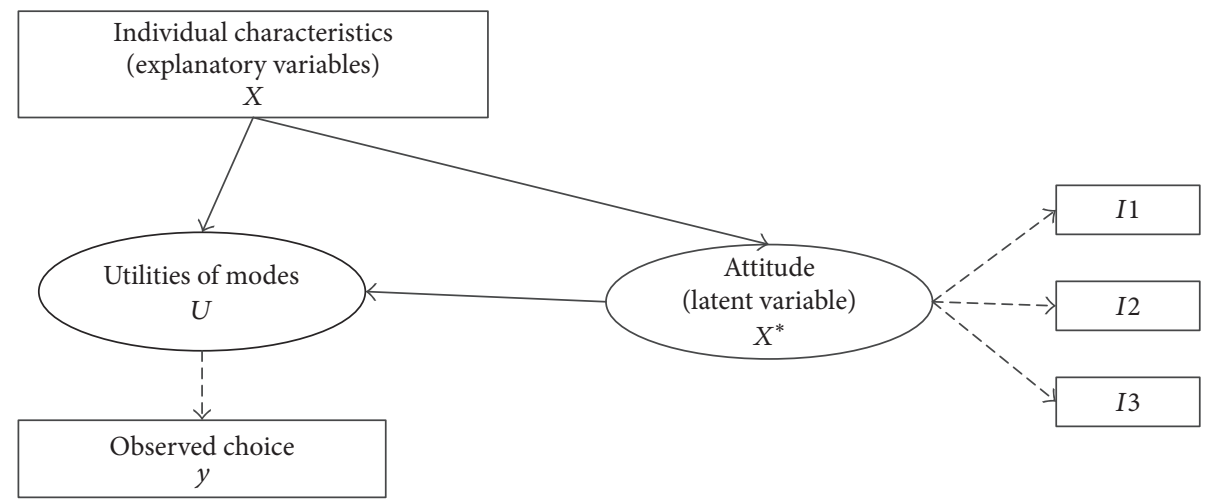

FIGURE 2: Modeling framework.

latent variable model in one framework. The most general framework has been proposed by Ben-Akiva et al. [30, 31] and it consists of two components. The measurement model component describes the relationship between the indicators and its corresponding latent variable, while the structural model component describes the complex relationships among the exogenous variable and endogenous variable. In this paper, we aim to examine the influences of objective variables and psychological variables on choosing the modes of walking or cycling to work. For this purpose, we construct the HCM framework with a latent variable "attitude towards walking or cycling." To measure the latent variable, three attitudinal indicators are used. The modeling framework is presented in Figure 2.

For the HCM framework, the structural model and the measurement model are described as follows.

Structural equations part:

$$
\begin{aligned}
& X_{n}^{*}=\gamma X_{n}+\sigma_{n}, \quad \sigma_{n} \sim N(0,1), \\
& U_{n}=\beta_{n} X_{n}+\Gamma X_{n}^{*}+\varepsilon_{n},
\end{aligned}
$$

where $X^{*}$ is the latent variable, $X_{n}$ is the exogenous variable, and $\sigma_{n}$ is the random error term. $U_{n}$ is the utility of the nonmotorized travel mode, and $\varepsilon_{n}$ is the independently, identically distributed (i.i.d.) extreme value. $\beta_{n}, \gamma$, and $\Gamma$ are the estimated parameters.

Measurement equations part:

$$
\begin{aligned}
& I_{n}=\alpha_{n}+\lambda_{n} X_{n}+v_{n}, \\
& y_{n}= \begin{cases}1, & \text { if } U_{i}=\max \left(U_{j}\right) \\
0, & \text { otherwise, }\end{cases}
\end{aligned}
$$

where $I_{n}$ is the indicator of the latent variable $\left(X^{*}\right), v_{n}$ is the random error term, and $y$ is a choice indicator, taking the value one if the nonmotorized travel mode is chosen, and 0 otherwise. In this study, the maximum likelihood techniques are used to estimate the model parameters. For the HCM method, the likelihood function for a given observation is the joint probability of observing the travel mode choice and the attitudinal indicators that can be obtained as follows:

$$
\begin{gathered}
f\left(y_{n}, \ln \mid X_{n} ; \alpha, \beta, \lambda\right)=\int_{X^{*}} P\left(y_{n} \mid X_{n}, X^{*} ; \beta\right) \\
\cdot f\left(I \mid X_{n}, X^{*} ; \alpha\right) f\left(X^{*} \mid X_{n} ; \lambda\right) d X^{*} .
\end{gathered}
$$

In order to examine the role of latent attitude variable played in travel mode choice behavior, a comparison was conducted between the traditional model and the proposed model. Based on the hybrid choice model, the indirect effects and total effects of social factors on travel mode choice through the mediating latent variable are calculated. Therefore, the intermediary nature of the attitudes to walking and cycling on commute mode choice would be confirmed.

\section{Data Sources and Description}

4.1. Questionnaire Design. The survey questionnaire is mainly composed of three parts, as shown in Table 1. The first two parts are to collect the individual and household characteristics (e.g., age, gender, education, occupation, income, bus card ownership, driver license, household children, bicycle ownership, and car ownership). The third part aims to collect the respondents' attitudes towards walking and cycling. Considering the immeasurability of subjective factors, three indicators were designed to measure 
TABLE 1: Objective variables used in models and description.

\begin{tabular}{|c|c|}
\hline Variable name & Variable description \\
\hline \multicolumn{2}{|c|}{ Individual characteristics } \\
\hline Age & $1=$ below 35 years old; $2=35$ to 55 years old; $3=$ over 55 years old \\
\hline Gender & $1=$ male; 2 = female \\
\hline Education & $1=$ low (junior school); $2=$ medium (junior college); $3=$ high (bachelor, master, or Ph.D.) \\
\hline Occupation & $1=$ government-related job; 2 = others \\
\hline Income & $1=$ less than $2000 ¥ ; 2=2000-8000 ¥ ; 3=$ more than $8000 ¥$ \\
\hline Bus card & $1=$ individual with a bus card; $2=$ without a bus card \\
\hline Driver license & $1=$ individual with a driver license; 2 = without a driver license \\
\hline \multicolumn{2}{|c|}{ Household characteristics } \\
\hline Household children & $1=$ household with one or more children; $2=$ without children \\
\hline Car ownership & $1=$ household with one or more cars available; $2=$ without \\
\hline Bicycle ownership & $1=$ household with one or more bicycles available; 2 = without \\
\hline \multicolumn{2}{|l|}{ Mode choice } \\
\hline Mode choice & $1=$ walking and cycling; $2=$ others \\
\hline
\end{tabular}

the respondents' attitudes towards walking and cycling in this study. The indicators are described as follows: nonmotorized travel mode can help to improve environmental pollution $\left(I_{1}\right)$, walking or cycling to work can get physical exercise and keep fit $\left(I_{2}\right)$, and nonmotorized travel mode can satisfy daily travel $\left(I_{3}\right)$. Agreements or disagreements of all those descriptions were measured by five-point Likert Scale: disagree strongly, disagree a little, neither agree nor disagree, agree a little, and agree strongly which were coded as 1, 2, 3, 4 , and 5 , respectively.

The survey was conducted in Zhenjiang city during the year 2015 in China. Zhenjiang city is located in the southwest of Jiangsu Province, the lower reaches of the Yangtze River. With regard to the political status, economic development, and city scale, Zhenjiang belongs to China's third-tier cities. The survey data used in this paper was obtained from the OpenITS website by Jiangsu University. At last, 2941 respondents completed the surveys, and 2660 valid samples were selected. It is worth mentioning that nearly half $(41.7 \%)$ of the respondents live within five kilometers from workplace. Generally speaking, there is a possibility for the respondents to choose walking or cycling to commute. As is well known, for the long-distance travel, it is more likely to choose motorized travel modes to commute $[6,32]$. For the small cities like Zhenjiang, it is meaningful and valuable to investigate the walking or cycling travel behavior. In this study, considering the general travel distance of walking and cycling, the respondents with more than five kilometers' commuting distance were removed. Finally, 1110 respondents were selected for further study.

4.2. Descriptive Statistics. In the final sample, $59.7 \%$ of the respondents are males, and $40.3 \%$ are females. $74.3 \%$ of the respondents are below 35 years old, $22.0 \%$ are between 35 and 55 years old, and $3.7 \%$ are above 55 years old. With regard to the education level, $11.9 \%$ of the respondents are below junior college level, $39.8 \%$ have undergraduate degrees, and $48.3 \%$ have graduate degrees. In terms of the occupation, $8.0 \%$ of the respondents are government staffs. As to the income, $40.8 \%$ of the respondents are low income people, $55.1 \%$ are the middle-income group, and $4.1 \%$ are high-income group. As for the household children, $49.3 \%$ of the respondents' household have children and $50.7 \%$ of the respondents have no kids. According to the survey results, $51.5 \%$ of the respondents choose walking or cycling to commute. Figure 3 presents the respondents' responses to the attitude towards nonmotorized travel. Descriptive statistics of three indicators of the latent variable are shown in Table 2.

\section{Result Analysis}

5.1. Model Fit. The model parameters were estimated using the maximum likelihood method based on the $M$-plus software with 1,000 bootstrap draws. The model fit information is listed in Table 3, indicating that the hybrid choice model obtains a good fit [33]. With regard to the internal consistency of the indicators, as shown in Table 4, Cronbach's alpha value is larger than the threshold value of 0.60 , indicating that the selected indicators are reliable to measure the underlying latent variable [34]. Meanwhile, for each indicator variable, the factor loading coefficient is significant at the $99 \%$ level. In other words, all the observed indicator variables contribute to capture of the unobservable latent variable.

5.2. Modeling Results. Using the survey data collected in China cities, a comparison between the traditional model and the hybrid choice model is conducted. The estimation results of both modesl are shown in Table 5. Comparing the traditional model and the hybrid choice model, it is obviously seen that the integrated model indeed provides greater explanatory power with respect to the travel mode choice, indicating that incorporating the latent variable into the discrete choice model improved the overall fitness of 


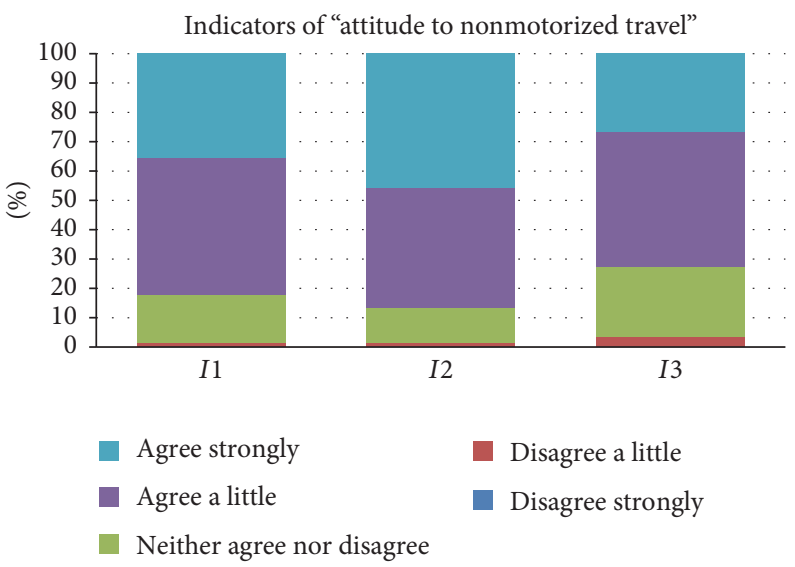

FIGURE 3: Indicators of latent variable.

TABLE 2: Latent variable and indicators.

\begin{tabular}{llcc}
\hline Indicators & Indicator description & Mean & St. Dev. \\
\hline$I_{1}$ & Nonmotorized travel mode can help to improve environmental pollution & 4.16 & 0.747 \\
$I_{2}$ & Walking or cycling to work can get physical exercise and keep fit & 4.31 & 0.738 \\
$I_{3}$ & I would like to choose nonmotorized travel mode to satisfy daily travel & 3.95 & 0.812 \\
\hline
\end{tabular}

Note. 1 = disagree strongly, 2 = disagree a little, 3 = neither agree nor disagree, 4 = agree a little, 5 = agree strongly.

TABLE 3: Goodness-of-fit of model.

\begin{tabular}{lll}
\hline Indicators & Description & $\begin{array}{c}\text { Values } \\
\text { Cut-off value }\end{array}$ \\
\hline$\chi^{2}$ & $\begin{array}{l}\text { Measuring the differences between the observed } \\
\text { covariance matrices and model-based covariance } \\
\text { matrices. }\end{array}$ & $\begin{array}{c}\text { Smaller } \chi^{2} \\
\text { shows better } \\
\text { model fit. }\end{array}$ \\
\hline CFI & Measuring noncenter parameter improvement. & 0.97 \\
\hline TLI & $\begin{array}{l}\text { Measuring the discrepancy between the observed } \\
\text { sample matrix and the theory matrix. }\end{array}$ & 0.99 \\
\hline RMSEA & $\begin{array}{l}\text { Measuring the difference of each degree of } \\
\text { freedom. }\end{array}$ & 0.01 \\
\hline SRMR & $\begin{array}{l}\text { Measuring the approximation error of each } \\
\text { degree of freedom. }\end{array}$ & 0.01 \\
\hline
\end{tabular}

Note. CFI is Comparative Fit index; TLI is Tucker Lewis index; SRMR is Standardized Root Mean Square Residual; RMSEA is Root Mean Square Error of Approximation.

TABLE 4: Factor loading coefficients for the indicators of the latent variable.

\begin{tabular}{lccc}
\hline Indicators & & Attitude towards nonmotorized travel & \\
& Cronbach's alpha & Parameter & $t$-stat \\
\hline$I_{1}$ & & 0.590 & 18.727 \\
$I_{2}$ & 0.620 & 0.622 & 19.736 \\
$I_{3}$ & & 0.645 & 20.309 \\
\hline
\end{tabular}

the model. Specifically, the likelihood ratio index improves from 0.313 to 0.364 . Besides, the Akaike information criterion (AIC) and adjusted Bayesian information criterion (BIC) of the integrated model are lower [35]. And more importantly, the influence of the latent attitude variable is positively significant at the $90 \%$ level, indicating that the attitude to walking and cycling plays a critical role in the nonmotorized travel mode choice. From this point, this finding might be very helpful to encourage the green modes [36].

As to the individual characteristics, there is no difference between the male and female for the nonmotorized travel mode choice. However, it is significantly related to the factors of age, education, occupation, income, and household children. Specifically, younger and older travelers are more 
TABLE 5: Estimation results for the traditional and the hybrid choice model.

\begin{tabular}{|c|c|c|c|c|}
\hline \multirow{2}{*}{ Variables } & \multicolumn{2}{|c|}{ Traditional model } & \multicolumn{2}{|c|}{ Hybrid choice model } \\
\hline & Parameter & $t$-stat & Parameter & $t$-stat \\
\hline Constant & 0.547 & $4.433^{* *}$ & 0.547 & $4.433^{* *}$ \\
\hline \multicolumn{5}{|c|}{ Household characteristics } \\
\hline Household children & -0.058 & $-1.959^{*}$ & -0.058 & $-1.969^{* *}$ \\
\hline Bicycle ownership & 0.243 & $8.444^{* *}$ & 0.245 & $8.518^{* *}$ \\
\hline Car ownership & -0.046 & -1.471 & -0.045 & -1.431 \\
\hline Bus card & -0.042 & -1.445 & -0.043 & -1.485 \\
\hline Driver license & -0.064 & $-2.105^{* *}$ & -0.066 & $-2.148^{* *}$ \\
\hline \multicolumn{5}{|c|}{ Individual characteristics } \\
\hline Gender & 0.016 & 0.573 & 0.013 & 0.489 \\
\hline \multicolumn{5}{|l|}{ Age } \\
\hline Age-1 & 0.115 & $3.368^{* *}$ & 0.113 & $3.310^{* *}$ \\
\hline Age-3 & 0.059 & $2.086^{* *}$ & 0.059 & $2.056^{* *}$ \\
\hline \multicolumn{5}{|l|}{ Education } \\
\hline Education-1 & 0.005 & 1.624 & 0.053 & $1.711^{*}$ \\
\hline Education-3 & 0.089 & $2.780^{* *}$ & 0.087 & $2.713^{* *}$ \\
\hline Government & -0.054 & $-1.969^{* *}$ & -0.056 & $-2.036^{* *}$ \\
\hline \multicolumn{5}{|l|}{ Income } \\
\hline Income-1 & 0.171 & $5.494^{* *}$ & 0.165 & $5.259^{* *}$ \\
\hline Income-3 & -0.011 & -0.395 & -0.013 & -0.453 \\
\hline \multicolumn{5}{|l|}{ Latent variables } \\
\hline Attitude & - & - & 0.056 & $1.673^{*}$ \\
\hline Observations & \multicolumn{2}{|c|}{1110} & \multicolumn{2}{|c|}{1110} \\
\hline LRI & \multicolumn{2}{|c|}{0.313} & \multicolumn{2}{|c|}{0.364} \\
\hline AIC & \multicolumn{2}{|c|}{8600.808} & \multicolumn{2}{|c|}{8267.361} \\
\hline Adjust BIC & \multicolumn{2}{|c|}{8670.571} & \multicolumn{2}{|c|}{8311.986} \\
\hline
\end{tabular}

Note. LRI is likelihood ratio index, $\mathrm{LRI}=1-\left(\mathrm{LL} \kappa / \mathrm{LL} \kappa_{0}\right)$, and $\mathrm{LL} \kappa_{0}$ is the $\log$-likelihood value when all the parameters are set equal to zero; AIC is Akaike information criterion; BIC is Bayesian information criterion; * indicates significant values at the $90 \%$ level; $* *$ indicates significant values at the $95 \%$ level.

likely to choose the walking or cycling mode to commute than middle-aged travelers. With respect to the educational attainment, it is found that higher level and lower level of them were both associated with a larger likelihood of choosing the walking or cycling mode. In addition, as expected, the people with low income tend to use the active travel mode choices. Government-related people are less likely to use the active travel mode choices. In terms of the household characteristics, it is found that the people from the household with children show less intention to choose the walking or cycling mode to commute. This may be due to the fact that it would be more convenient for parents to pick up their children on the way from/to work. As expected, the people owning a bicycle are more likely to choose active travel mode to commute, while the factor of driver license has a significantly negative effect. Therefore, in this context, in order to promote the walking or cycling mode, it is a feasible strategy to provide vast bicycles and improve the bike-sharing service in China cities (e.g., Ofo, Mobike).

5.3. Indirect Effects and Total Effects. With the advantage of hybrid choice model in mind, as displayed in Table 6, the indirect effect and the total effect are also calculated. For the model results, though the indirect effects of all the observable variables are insignificant, they do have negligible influences on the total final effects of the variables on walking or cycling mode choice. The total effects are the outcome of the direct effects and the indirect effects. Due to the mediating effect of the latent variable, the effect of variables on the mode choice may be strengthened or weakened [37]. As the model results shown, the indirect effects of education and bicycle ownership are negative, while the direct effects and the total effects are both positive. It means that the positive effect of low level education and bicycle ownership are both weakened for the intermediary role of the attitude to walking or cycling. Therefore, the indirect effect of the factors on travel mode choice cannot be ignored. Similar examples relate to the factors of job type, children, bus card, and driver license.

\section{Conclusions}

Transport-related problems, such as automobile dependence, traffic congestion, and greenhouse emissions, lead to a great burden on the environment. In developing countries like China, in order to improve the air quality, promoting sustainable travel modes to reduce the automobile usage 
TABLE 6: Estimation results for the indirect and total effects of observed variables.

\begin{tabular}{|c|c|c|c|c|}
\hline \multirow{3}{*}{ Variables } & \multicolumn{4}{|c|}{ Walking and cycling } \\
\hline & \multicolumn{2}{|c|}{ Indirect effect } & \multicolumn{2}{|c|}{ Total effect } \\
\hline & Parameter & $t$-stat & Parameter & $t$-stat \\
\hline Gender & 0.002 & 0.907 & 0.016 & 0.573 \\
\hline \multicolumn{5}{|l|}{ Age } \\
\hline Age-1 & 0.002 & 0.686 & 0.115 & $3.368^{* *}$ \\
\hline Age-3 & 0.001 & 0.394 & 0.059 & $2.086^{* *}$ \\
\hline \multicolumn{5}{|l|}{ Education } \\
\hline Education-1 & -0.003 & -0.931 & 0.050 & 1.624 \\
\hline Education-3 & 0.002 & 0.763 & 0.089 & $2.780^{* *}$ \\
\hline Government & 0.002 & 0.766 & -0.054 & $-1.969^{* *}$ \\
\hline \multicolumn{5}{|l|}{ Income } \\
\hline Income-1 & 0.006 & 1.396 & 0.171 & $5.494^{* *}$ \\
\hline Income-3 & 0.002 & 0.676 & -0.011 & -0.395 \\
\hline Household children & 0.000 & 0.104 & -0.058 & $-1.959^{* *}$ \\
\hline Bicycle ownership & -0.002 & -0.803 & 0.243 & $8.444^{* *}$ \\
\hline Car ownership & -0.001 & -0.500 & -0.046 & -1.471 \\
\hline Bus card & 0.001 & 0.477 & -0.042 & $-1.445^{* *}$ \\
\hline Driver license & 0.001 & 0.507 & -0.064 & $-2.105^{* *}$ \\
\hline
\end{tabular}

Note. $*$ indicates significant values at the $90 \%$ level. $* *$ indicates significant values at the $95 \%$ level.

is gradually recognized as an emerging national concern. Though there are many studies related to the physically active modes (e.g., walking and cycling), the research on the influence of attitudes to active modes on travel behavior is limited, especially in China. Hence, this paper focuses on examining the impact of attitudes to walking and cycling on commute mode choice.

Using the survey data collected in China cities, an integrated discrete choice model and the structural equation model are proposed. By applying the hybrid choice model, not only the role of the latent attitude played in travel mode choice, but also the indirect effects of social factors on travel mode choice are obtained. The comparison indicates that the hybrid choice model outperforms the traditional model. This study is expected to provide a better understanding for urban planners on the influential factors of green travel modes. For this study, it should be noted that the built environment has an important effect on travel mode choice [38]. However, due to the availability of land use data, the built environment measurements are not included in the model. For future studies, it is necessary to incorporate the built environment factors and attitudes into the travel behavior model.

\section{Conflicts of Interest}

The authors declare that they have no conflicts of interest.

\section{Acknowledgments}

This work is supported by the National Natural Science Foundation of China (71503018, U1564212, and U1664262).

\section{References}

[1] N. Cavill, H. Rutter, and A. Hill, "Action on cycling in primary care trusts: results of a survey of Directors of Public Health," Public Health, vol. 121, no. 2, pp. 100-105, 2007.

[2] D. R. Bassett, J. Pucher Jr., R. Buehler, D. L. Thompson, and S. E. Crouter, "Walking, cycling, and obesity rates in Europe, North America and Australia," Journal of Physical Activity and Health, vol. 5, no. 6, pp. 795-814, 2008.

[3] A. Goodman, "Walking, cycling and driving to work in the english and welsh 2011 census: trends, socio-economic patterning and relevance to travel behaviour in general," PLOS ONE, vol. 8, no. 8, Article ID e71790, 2013.

[4] R. Cervero, "Built environments and mode choice: toward a normative framework," Transportation Research Part D Transport and Environment, vol. 7, no. 4, pp. 265-284, 2002.

[5] Y. O. Susilo and K. Maat, "The influence of built environment to the trends in commuting journeys in the Netherlands," Transportation, vol. 34, no. 5, pp. 589-609, 2007.

[6] G. Vandenbulcke, C. Dujardin, I. Thomas et al., "Cycle commuting in Belgium: Spatial determinants and 're-cycling' strategies," Transportation Research Part A: Policy and Practice, vol. 45, no. 2, pp. 118-137, 2011.

[7] C. L. Antonakos, "Environmental and travel preferences of cyclists," Transportation Research Record, vol. 1438, pp. 25-33, 1994.

[8] M. An and M. Chen, "Estimating Nonmotorized Travel Demand," Transportation Research Record, vol. 2002, no. 1, pp. 18-25, 2007.

[9] D. A. Rodríguez and J. Joo, "The relationship between nonmotorized mode choice and the local physical environment," Transportation Research Part D: Transport and Environment, vol. 9, no. 2, pp. 151-173, 2004. 
[10] E. Heinen, K. Maat, and B. van Wee, "The effect of workrelated factors on the bicycle commute mode choice in the Netherlands," Transportation, vol. 40, no. 1, pp. 23-43, 2013.

[11] J. Anable, “'Complacent Car Addicts'; or 'Aspiring Environmentalists'? Identifying travel behaviour segments using attitude theory," Transport Policy, vol. 12, no. 1, pp. 65-78, 2005.

[12] P. O. Plaut, "Non-motorized commuting in the US," Transportation Research Part D: Transport and Environment, vol. 10, no. 5, pp. 347-356, 2005.

[13] T. Ryley, "Estimating cycling demand for the journey to work or study in West Edinburgh, Scotland," Transportation Research Record: Journal of the Transportation Research Board, vol. 1982, pp. 187-193, 2006.

[14] K. Nurul Habib, X. Han, and W. H. Lin, "Joint modelling of propensity and distance for walking-trip generation," Transportmetrica A: Transport Science, vol. 10, no. 5, pp. 420-436, 2014.

[15] J. Parkin, M. Wardman, and M. Page, "Estimation of the determinants of bicycle mode share for the journey to work using census data," Transportation, vol. 35, no. 1, pp. 93-109, 2008.

[16] M. Khan, K. M. Kockelman, and X. Xiong, "Models for anticipating non-motorized travel choices, and the role of the built environment," Transport Policy, vol. 35, pp. 117-126, 2014.

[17] J. D. Hunt and J. E. Abraham, "Influences on bicycle use," Transportation, vol. 34, no. 4, pp. 453-470, 2007.

[18] I. Ajzen, Attitudes, Personality, and Behavior, McGraw-Hill Education, UK, 2005.

[19] R. A. Daziano and D. Bolduc, "Incorporating proenvironmental preferences towards green automobile technologies through a Bayesian hybrid choice model," Transportmetrica A: Transport Science, vol. 9, no. 1, pp. 74-106, 2013.

[20] D. Bolduc, N. Boucher, and R. Alvarez-Daziano, "Hybrid choice modeling of new technologies for car choice in Canada," Transportation Research Record: Journal of the Transportation Research Board, vol. 2082, pp. 63-71, 2008.

[21] M. V. Johansson, T. Heldt, and P. Johansson, "The effects of attitudes and personality traits on mode choice," Transportation Research Part A: Policy and Practice, vol. 40, no. 6, pp. 507-525, 2006.

[22] D. Mcfadden, M. Ben-Akiva, and T. Morikawa, "Discrete choice models incorporating revealed preferences and psychometric data," Advances in Econometrics, vol. 16, no. 1, pp. 29-55, 2002.

[23] R. Maldonado-Hinarejos, A. Sivakumar, and J. W. Polak, "Exploring the role of individual attitudes and perceptions in predicting the demand for cycling: a hybrid choice modelling approach," Transportation, vol. 41, no. 6, pp. 1287-1304, 2014.

[24] J. Dill and K. Voros, "Factors affecting bicycling demand: Initial survey findings from the Portland, Oregon, region," Transportation Research Record, vol. 2031, pp. 9-17, 2007.

[25] B. Gatersleben and K. M. Appleton, "Contemplating cycling to work: attitudes and perceptions in different stages of change," Transportation Research Part A: Policy and Practice, vol. 41, no. 4, pp. 302-312, 2007.

[26] S. Choo and P. L. Mokhtarian, "What type of vehicle do people drive? The role of attitude and lifestyle in influencing vehicle type choice," Transportation Research Part A: Policy and Practice, vol. 38, no. 3, pp. 201-222, 2004.

[27] M. Kamargianni and A. Polydoropoulou, "Hybrid choice model to investigate effects of teenagers' attitudes toward walking and cycling on mode choice behavior," Transportation Research Record, no. 2382, pp. 151-161, 2013.

[28] K. G. Jöreskog and A. S. Goldberger, "Estimation of a model with multiple indicators and multiple causes of a single latent variable," Journal of the American Statistical Association, vol. 70, no. 351, part 1, pp. 631-639, 1975.

[29] Y. Zhu, Y. Wang, and C. Ding, "Investigating the influential factors in the metro choice behavior: evidences from Beijing, China," KSCE Journal of Civil Engineering, vol. 20, no. 7, pp. 2947-2954, 2016.

[30] M. Ben-Akiva, D. Mcfadden, K. Train, J. Walker, C. Bhat, M. Bierlaire et al., "Hybrid choice models: progress and challenges," Marketing Letters, vol. 13, no. 3, pp. 163-175, 2002.

[31] M. Ben-Akiva, J. Walker, A. T. Bernardino, D. A. Gopinath, T. Morikawa, and A. Polydoropoulou, "Integration of choice and latent variable models," Perpetual Motion: Travel Behaviour Research Opportunities and Application Challenges, pp. 431-470, 2002.

[32] N. C. McDonald, "Children's mode choice for the school trip: The role of distance and school location in walking to school," Transportation, vol. 35, no. 1, pp. 23-35, 2008.

[33] R. C. MacCallum, M. W. Browne, and H. M. Sugawara, "Power analysis and determination of sample size for covariance structure modeling," Psychological Methods, vol. 1, no. 2, pp. 130-149, 1996.

[34] R. P. Bagozzi and Y. Yi, "On the evaluation of structural equation models," Journal of the Academy of Marketing Science, vol. 16, no. 1, pp. 74-94, 1988.

[35] C. Ding, S. Mishra, G. Lu, J. Yang, and C. Liu, "Influences of built environment characteristics and individual factors on commuting distance: a multilevel mixture hazard modeling approach," Transportation Research Part D: Transport and Environment, vol. 51, pp. 314-325, 2017.

[36] X. Ma, Y. J. Wu, Y. Wang, F. Chen, and J. Liu, "Mining smart car data for transit riders' travel patterns," Transportation Research Part C: Emerging Technologies, vol. 36, pp. 1-12, 2013.

[37] C. Ding, D. Wang, C. Liu, Y. Zhang, and J. Yang, "Exploring the influence of built environment on travel mode choice considering the mediating effects of car ownership and travel distance," Transportation Research Part A: Policy and Practice, vol. 100, pp. 65-80, 2017.

[38] C. Ding, Y. Lin, and C. Liu, "Exploring the influence of built environment on tour-based commuter mode choice: a cross-classified multilevel modeling approach," Transportation Research Part D: Transport and Environment, vol. 32, pp. 230238, 2014. 


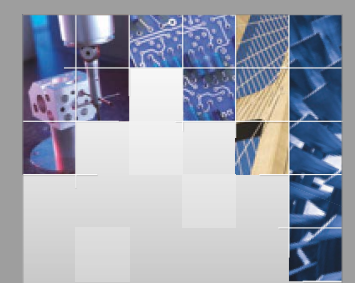

\section{Enfincering}
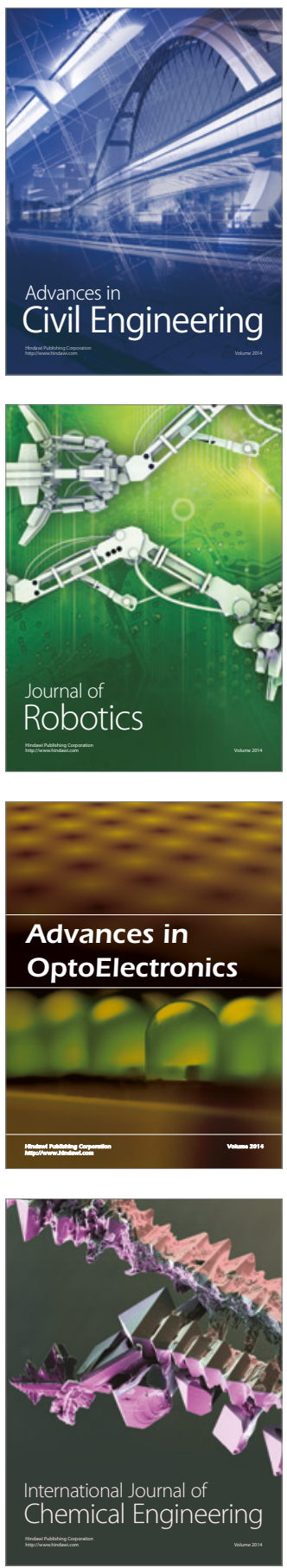

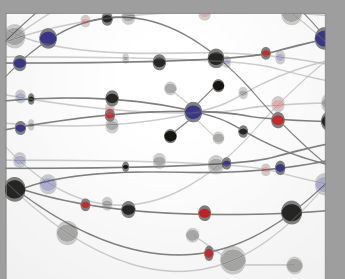

The Scientific World Journal

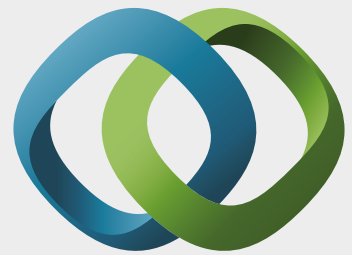

\section{Hindawi}

Submit your manuscripts at

https://www.hindawi.com
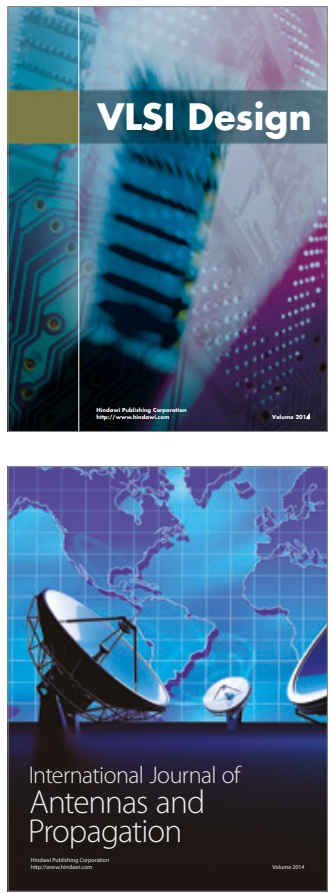

\section{Rotating}

Machinery
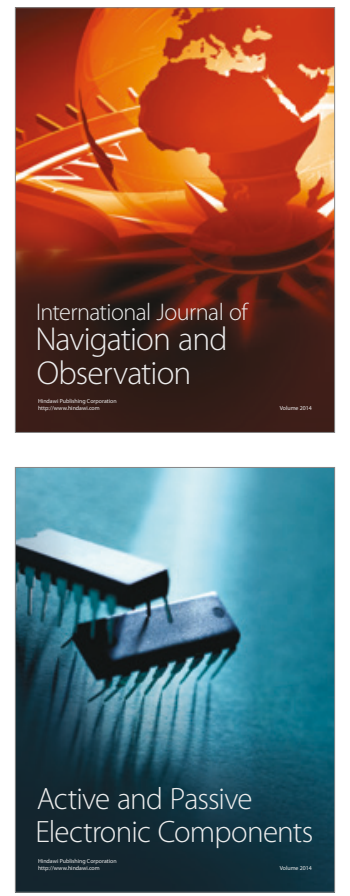
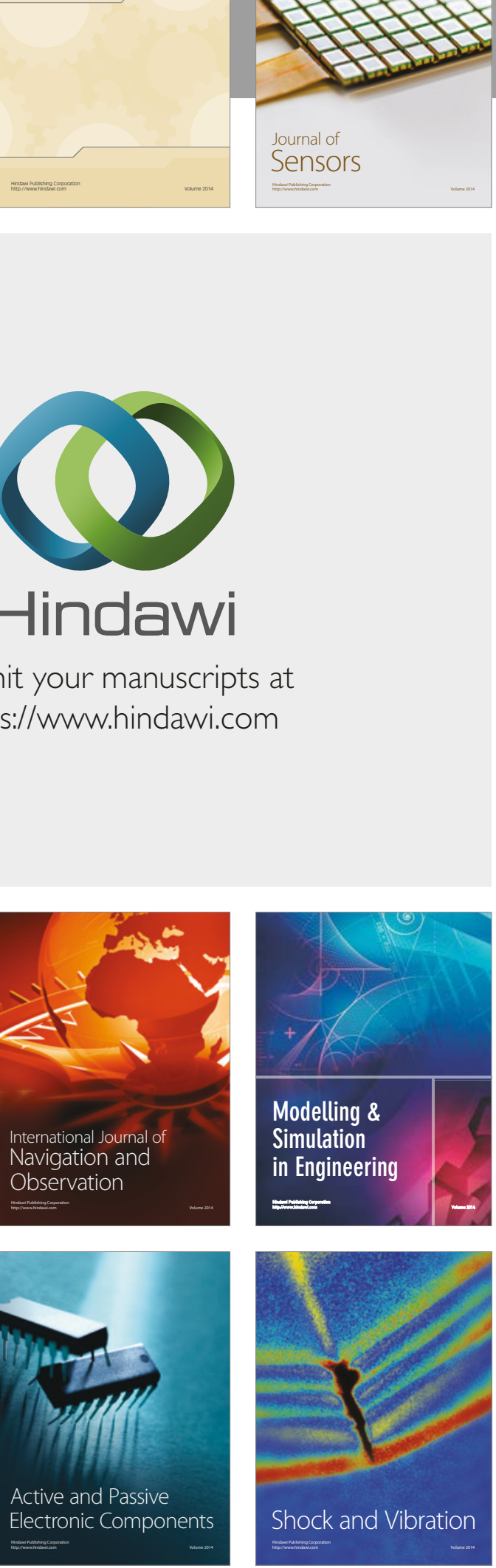
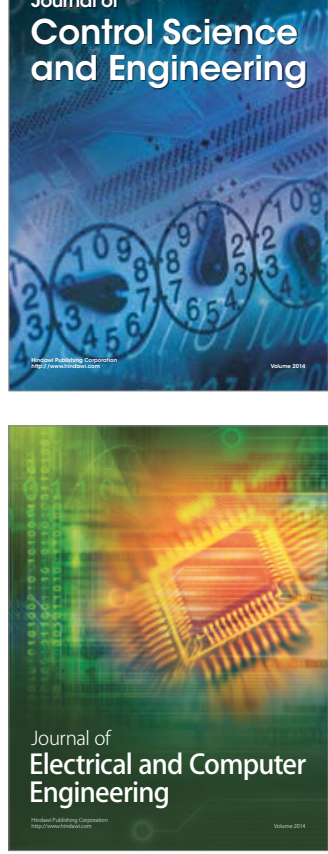

Distributed

Journal of

Control Science

and Engineering
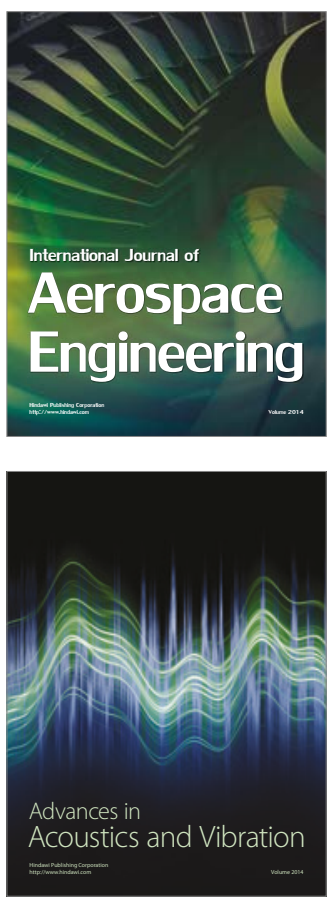

Sensor Networks 